\title{
Editorial
}

\section{One Hundred Years of the Electron}

On the 30 April 1897, J.J. Thomson gave the Friday evening Discourse at the Royal Institution in London. His subject was "Cathode rays" and he offered the first convincing evidence that these rays consisted of charged particles with a most unusual property: the ratio of their mass to charge was far smaller than that of any known particle. Thomson clearly believed that their charge was normal and that they were hence tinier than atoms but it was only in 1899 that he demonstrated that the charge was indeed the same as that of ions: "...we have clear proof that the ions have a much smaller mass than ordinary atoms; so that in the convection of negative electricity at low pressures, we have something smaller even than the atom, something which involves the splitting up of the atom, inasmuch as we have taken from it a part, though only a small one, of its mass...

From what we have seen, this negative ion must be a quantity of fundamental importance in any theory of electrical action; indeed, it seems not improbable that it is the fundamental quantity in terms of which all electrical processes can be expressed."

Why was it necessary for Thomson to perform his experiments and why did he name these new particles "electrons"? After all, the cathode rays had been discovered nearly 40 years earlier by Plücker, in Bonn, and numerous attempts to elucidate their nature had been made, notably in Germany by Plücker himself, his pupil Hittorf, Goldstein, Hertz and Kaufmann and in England by Varley and Crookes among others. The German school believed that the rays were some kind of oscillation of the æether, probably transverse, governed by laws that remained to be discovered. They rejected the idea that the rays consisted of charged particles, favoured by the English camp, on the grounds that the rays were not deflected by electrostatic fields; this result, obtained by Hertz, was particularly unfortunate and it was not until Thomson repeated the experiment in 1897 with a better vacuum that it became apparent that Hertz's negative finding was due to the poor vacuum in his tube. A paper by Varley of 1870 illustrates the English viewpoint: "This experiment, in the author's opinion, indicates that this arch is composed of attenuated particles of matter projected from the negative pole by electricity in all directions, but that the magnet controls their course...the author has been informed more than once, by captains of vessels, that when men have been struck by lightning a burn has been left upon the skin of the same shape as the object from which the discharge flew. In one instance, he was informed that some brass numbers attached to the rigging, from which the discharge passed to the sailor, were imprinted on his skin.

It is now seen that this is perfectly possible if the discharge be a negative one - that is if the man be + to the brass number."

In answer to the second question, why call the particles "electrons", we find that Thomson carefully avoided the word - in 1897, even though Fitzgerald (who introduced the published 
report of Thomson's Royal Institution lecture) used the word freely - in 1899 and even in 1906 when he was awarded his Nobel Prize! "Electron" had been introduced by G.J. Stoney in a lecture to the Royal Dublin Society in 1891, in which he advocated the use of a new system of units based on three naturally occurring quantities (the velocity of light, the gravitational constant and the elementary charge) instead of the arbitrary centimetre, gramme and second. The electron was thus strictly speaking not a physical object but a unit, like the volt or the metre. Nevertheless, even before Thomson's discovery of 1897 , scientists were using the word loosely to mean an object carrying an elementary charge and soon after 1897 it was in common use. The historians of science assume that Thomson avoided the word to emphasize the distinction between the unit and the particle, in the same way that we do not call resistors "ohms", but another explanation is tempting. Stoney, however good a scientist he may have been, had a reputation for writing on somewhat outlandish or eccentric subjects. His proposals for natural units, which sound very modern to our ears, may have seemed bizarre to his contemporaries, particularly as he introduced new vocabulary as well. Thus in introducing the "electron", he wrote: "...in electrolysis, a definite quantity of electricity, the same in all cases, passes for each chemical bond that is ruptured...the amount of this very remarkable quantity of electricity is about the twentiethet (that is, $1 / 10^{20}$ ) of the usual electromagnetic unit of electricity...This is the same as three-eleventhets $\left(3 / 10^{11}\right)$ of the much smaller C.G.S electrostatic unit of quantity. A charge of this amount is associated in the chemical atom with each bond...These charges, which it will be convenient to call electrons, cannot be removed from the atom; but they become disguised when atoms chemically unite." He invented a soidisant simplified form of musical notation, he published articles on how bacteria acquire energy and on insect locomotion. I believe it likely that, to a Cavendish Professor of Experimental Physics, Stoney was not to be taken seriously and Thomson's avoidance of the word introduced by Stoney reflected this attitude. Be this as it may, electron rapidly entered the language of science and even, more common parlance; in 1913, we find the Empire Review referring to "The imponderable electrons of sentiment and feeling which allow our far-away peoples and clans to cohere...".

By a happy coincidence, 1997 marks the centenary not only of the electron but of the cathoderay tube, introduced by Ferdinand Braun even before the nature of the rays was established: it had long been known that these rays were deflected by magnetic fields and Braun put this deflection to work in what was for long known in Germany as a Braun'sche Röhre.

For more than 20 years, the ballistics of charged particles was studied, by students of the aurora borealis and by designers of cathode-ray tubes and it was not until 1923 that the next major step forward was made, by Louis de Broglie, who associated a frequency, and hence a wavelength, with charged particles. It is ironic that, in contrast to the history of light optics, the wave optics of electrons was discovered before their geometrical optics. The latter had to await 1927, when Hans Busch, concerned with improving cathode-ray tube design, discovered that the effect of rotationally symmetric fields on electrons should be described by the same laws as that of a glass lens on light.

After that, our subject advanced rapidly. Gabor almost invented the electron lens, when he enveloped the focusing coil of a CRT in an iron yoke but sadly for him, he did not understand the physics of his design. In the early '30s, Ernst Ruska and Max Knoll, soon to be joined by Ruska's future brother-in-law, Bodo von Borries, confirmed Busch's theory and went on to build the first electron microscopes. In 1938, Baron Manfred von Ardenne built the first scanning electron microscope and even adumbrated the first STEM. Still in the 1930s, Hans Boersch came very close to holography, which had to await the inventive genius of Dennis Gabor in 1947 before becoming a reality. Still in the '30s, the theoreticians Walter Glaser and Otto Scherzer laid down the foundations of electron optics as we know it today. 
Although some 38 Siemens electron microscopes were in use during the wartime years, the main developments in that period come from the USA and Japan, where RCA and several Japanese firms were developing commercial instruments. The human side of the American involvement is vividly portrayed in a historical article by N. Rasmussen $\left({ }^{1}\right)$, in which we are told how the early RCA instruments were policed by a small group of experts (including T.F. Anderson). When Frances Seymour dared to publish without their permission, Anderson noted "...the artificial insemination gang at New York...published some lousy pictures of sperm in which they saw suction mouths in the head, a body, and a tail". (T.F. Anderson's notebook, 26 June 1941).

1965 saw the first commercial scanning electron microscope (the Cambridge Instrument Co. Stereoscan) and the first announcement, at an Institute of Physics conference on Nonconventional Microscopy, of the STEM by Albert Crewe. And in 1986, the Nobel prize was awarded to Ernst Ruska, for his electron microscope and to Binnig and Rohrer, for its latest descendent, the scanning tunnelling microscope.

Peter Hawkes CEMES-LOE-CNRS

Toulouse

$\left({ }^{1}\right)$ Rasmussen N., Making a machine instrumental: RCA and the wartime origins of biological electron microscopy in America, 1940-1945, Stud. Hist. Phil. Sci. 27 (1996) 311-349. 